\title{
De structuur van een consult - onderwijs en praktijk
}

M. Terluin, M.E. Andeweg, P.M. Boendermaker, J. Pols

\section{Samenvatting}

Inleiding: Bij het vaardigheidsonderwijs in Groningen wordt studenten geleerd een gestructureerd consult te voeren. Onderzocht is in hoeverre het 'onderwijsconsult' verschilt van consulten in de praktijk.

Methode: Vierdejaars studenten geneeskunde scoorden consulten van huisartsen en beantwoordden open vragen over verschillen tussen het onderwijsconsult en consulten van huisartsen.

Resultaten: Alle onderdelen van het onderwijsconsult komen voor in consulten van huisartsen, maar niet alle onderdelen komen bij elk consult aan bod. Praktijkconsulten verlopen minder gestructureerd. Dit heeft verschillende oorzaken: niet alles is altijd van toepassing, de arts kent de patiënt over het algemeen goed, er is weinig tijd, de arts heeft veel meer ervaring dan studenten, de diagnose is soms overduidelijk, soms is er aanleiding om direct lichamelijk onderzoek te doen, en er zijn veel vervolgconsulten.

Beschouwing: In het vaardigheidsonderwijs zou aandacht besteed moeten worden aan het voeren van vervolgconsulten en zou rekening gehouden moeten worden met situaties die aanleiding geven om direct lichamelijk onderzoek doen. Studenten leren dan om de structuur los te laten wanneer dat nodig is. (Terluin M, Andeweg ME, Boendermaker PM, Pols J. De structuur van een consult - onderwijs en praktijk. Tijdschrift voor Medisch Onderwijs 2002;21(2):50-56.)

Dit artikel is in verkorte vorm gepubliceerd in Huisarts en Wetenschap. Terluin M, Andeweg ME, Boendermaker PM, Pols J. De structuur van een consult - onderwijs en praktijk. Huisarts Wet 2000;43(13):563-5.

\section{Inleiding}

Aan de Faculteit der Medische Wetenschappen in Groningen wordt sinds 1993 gewerkt met het onderwijsprogramma Curriculum 2000. Bij het vaardigheidsonderwijs in dit curriculum leren studenten om een consult uit te voeren waarin zij anamnese, lichamelijk onderzoek en gespreksvaardigheden integreren. ${ }^{1}$ De structuur die zij voor dit consult aangeboden krijgen, is afgeleid van het consultmodel van Schouten. ${ }^{2}$ Het 'onderwijsconsult', zoals we het verder zullen noemen, kent drie fasen:
Vraagverheldering:

- contactreden

- hoofdklacht

- hulpvraag

- aanleiding voor komst

Diagnostiek:

- uitvragen van de zeven dimensies van de hoofdklacht (aard, lokalisatie, ernst, chronologie, ontstaan, beïnvloeding en beleving van de klacht)

- hypothesetoetsing

- lichamelijk onderzoek 
Afronding:

- samenvatting van de bevindingen uit de eerste twee fasen

- uitleg over de (differentiële) diagnose

- beleidsvoorstel

- bespreking uitvoering van het gekozen beleid

- besluit consult

Doel van dit onderwijs is de studenten zo goed mogelijk voor te bereiden op de latere praktijk. Het consultmodel van Schouten is echter gebaseerd op diens eigen ervaring in het begeleiden van studenten en artsen en niet op onderzoek van praktijkconsulten. De vraag is dus gewettigd in hoeverre dit model (en in het verlengde daarvan het onderwijsconsult) verschilt van wat er in de praktijk gebeurt. Literatuuronderzoek leverde slechts vier publicaties op waarin onderzoek naar praktijkconsulten wordt beschreven. ${ }^{3-6}$ In deze publicaties wordt terzijde aandacht besteed aan de fasering van een consult. Daarbij wordt de volgende indeling beschreven: opening - hoofdklacht onderzoek - diagnose - behandeling afronding. Aan de verdere onderverdeling van consulten in de praktijk wordt ook in deze publicaties geen aandacht besteed.

Een vergelijking met het onderwijsconsult kon op grond van deze beschrijvingen niet worden gemaakt. Dit was aanleiding voor een inventariserend onderzoek bij een aantal huisartsen op basis van de volgende vraagstelling:

1. In hoeverre komen onderdelen van het consult zoals dat in het onderwijs wordt getraind voor in consulten van huisartsen?

2. Hoe kunnen verschillen verklaard worden?

\section{Methode}

Aan het begin van het vierde studiejaar lopen alle studenten drie dagen stage in een huisartspraktijk. In het studiejaar
1998-1999 werd hun gevraagd om tijdens deze stage vier consulten te observeren aan de hand van een scoreformulier waarop alle onderdelen van het onderwijsconsult stonden vermeld. Per consult moest worden aangegeven welke onderdelen wel en niet aan bod kwamen. Ook moest worden aangegeven of het om een nieuw probleem (eerste consult) of om een vervolgconsult ging. Een vergelijkbaar formulier gebruiken studenten bij het vaardigheidsonderwijs om elkaar te observeren en feedback te geven. Ten tijde van het onderzoek hadden zij hiermee een jaar ervaring. Een separaat uitgevoerd experiment toonde aan dat zij voldoende in staat zijn tot betrouwbare en valide beoordelingen van de structuur van consulten van huisartsen. ${ }^{7}$ Naar aanleiding van hun observaties moesten de studenten drie open vragen beantwoorden:

- Wat zijn de meest opvallende verschillen tussen de huisartsconsulten en het onderwijsconsult?

- Wat zijn volgens jou de redenen voor deze verschillen?

- Wat zijn de opvattingen van de huisarts hierover?

De derde vraag werd beantwoord na een gesprek tussen student en huisarts over de eerste twee vragen. De student noteerde de opvattingen van de huisarts.

Alle scoreformulieren zijn geaccepteerd voor verwerking, ook als er minder dan vier consulten waren gescoord, of als de open vragen niet (alle) waren beantwoord. De data zijn verwerkt met SPSS. De antwoorden op de open vragen zijn door de auteurs in een iteratief kwalitatieve analyseprocedure ondergebracht in rubrieken. ${ }^{8}$

\section{Resultaten}

In september 1998 liepen 225 studenten stage bij 157 huisartsen; 68 huisartsen ontvingen tweemaal een student. Er wer- 
den 190 scoreformulieren geretourneerd (respons 84\%). In totaal werden 756 consulten gescoord. Van de respondenten vulden $167(88 \%)$ alle open vragen in.

Alle consultonderdelen uit het onderwijs werden door de studenten ook in de praktijk waargenomen (tabel 1). De contactreden uit de vraagverheldering en het beleid uit de afronding kwamen bijna altijd aan bod; de samenvatting aan het begin van de afronding werd het minst gescoord. In totaal werden 500 eerste consulten en 208 vervolgconsulten geobserveerd; bij 48 consulten was de des- betreffende vraag niet beantwoord. Contactreden, hoofdklacht, aard, lokalisatie, chronologie, ontstaan, hypothesetoetsing, lichamelijk onderzoek en uitleg diagnose kwamen bij vervolgconsulten significant minder vaak aan bod dan bij eerste consulten (tabel 1).

De studenten noemden gemiddeld drie verschillen tussen het onderwijsconsult en de praktijkconsulten. De meest voorkomende zijn: in de praktijk komen niet alle onderdelen bij elk consult aan bod en de volgorde van de onderdelen is meer variabel (tabel 2).

Tabel 1. Het wel/niet vóórkomen van consultonderdelen voor alle consulten, eerste consulten en vervolgconsulten (in percentages).

\begin{tabular}{|c|c|c|c|c|c|c|}
\hline & \multicolumn{2}{|c|}{$\begin{array}{l}\text { alle consulten } \\
n=756\end{array}$} & \multicolumn{2}{|c|}{$\begin{array}{l}\text { eerste consulten } \\
\qquad n=500\end{array}$} & \multicolumn{2}{|c|}{$\begin{array}{l}\text { vervolgconsulten } \\
\qquad n=208\end{array}$} \\
\hline & wel & niet & wel & niet & wel & niet \\
\hline \multicolumn{7}{|l|}{ fase 1} \\
\hline contactreden & 96 & 4 & 97 & 3 & 94 & $6^{*}$ \\
\hline aanleiding & 73 & 27 & 74 & 26 & 69 & 31 \\
\hline hulpvraag & 65 & 35 & 64 & 36 & 65 & 35 \\
\hline hoofdklacht & 94 & 6 & 95 & 5 & 90 & $10^{*}$ \\
\hline \multicolumn{7}{|l|}{ fase 2} \\
\hline aard & 69 & 31 & 72 & 28 & 60 & $40^{*}$ \\
\hline lokalisatie & 74 & 26 & 78 & 22 & 63 & $37^{*}$ \\
\hline ernst & 68 & 32 & 69 & 31 & 66 & 34 \\
\hline chronologie & 68 & 32 & 72 & 28 & 57 & $43^{*}$ \\
\hline ontstaan & 60 & 40 & 66 & 34 & 43 & $57^{*}$ \\
\hline beïnvloeding & 49 & 51 & 50 & 50 & 46 & 54 \\
\hline beleving & 53 & 47 & 51 & 49 & 55 & 45 \\
\hline hypothesetoetsing & 61 & 40 & 66 & 34 & 48 & $52^{*}$ \\
\hline lichamelijk onderzoek & 85 & 15 & 90 & 10 & 72 & $28^{*}$ \\
\hline \multicolumn{7}{|l|}{ fase 3} \\
\hline samenvatting & 24 & 76 & 24 & 76 & 24 & 77 \\
\hline uitleg diagnose & 75 & 25 & 78 & 23 & 67 & $34^{*}$ \\
\hline beleid & 96 & 4 & 96 & 4 & 97 & 3 \\
\hline bespreking uitvoering beleid & 85 & 15 & 85 & 15 & 86 & 14 \\
\hline afronding & 89 & 11 & 90 & 10 & 88 & 12 \\
\hline
\end{tabular}

${ }^{*}$ Consultonderdeel komt bij vervolgconsulten significant minder vaak aan de orde, $\mathrm{p}<0.05$. 
Tabel 2. Antwoorden op vraag 1. 'Wat zijn de meest opvallende verschillen tussen de huisartsconsulten en het onderwijsconsult?' Percentage respondenten ( $n=177)$ dat het desbetreffende antwoord gaf.

\section{antwoord}

inhoud van praktijkconsulten

niet elk consultonderdeel komt altijd aan bod 73

samenvatting mist

veel consultonderdelen komen wel aan bod

\section{met betrekking tot lichamelijk onderzoek in de praktijk}

anamnese en lichamelijk onderzoek door elkaar 20 lichamelijk onderzoek niet zo uitgebreid $\quad 18$

snel over op lichamelijk onderzoek

minder ontkleedinstructie/minder kleding uit

\section{verloop van praktijkconsulten}

variabele volgorde, minder strak ingedeeld

sneller/korter

effectiever/gerichter

natuurlijker

patiënten vertellen uit zichzelf meer

efficiënter

Zowel de studenten als de huisartsen noemden diverse verklaringen voor de verschillen: de arts kent zijn patiënt al, hij heeft minder tijd voor zijn consult, hij heeft ervaring, hij heeft een eigen stijl en het gaat in de praktijk vaak om vervolgconsulten. Daarnaast werd door studenten gezegd dat niet alle onderdelen bij elk consult van toepassing zijn, dat het onderwijs een leersituatie is, dat de patiënten in het onderwijs niet echt zijn, dat echte patiënten uit zichzelf meer vertellen dan simulatiepatiënten, dat de diagnose in de praktijk soms overduidelijk is, en dat de situatie soms aanleiding geeft om eerder in het consult lichamelijk onderzoek te doen.

De huisartsen merkten verder op dat de structuur van het onderwijsconsult voor hen een hulpmiddel is bij complexe

problemen en dat het onderwijsconsult volgens hen een goed leermiddel is. Over het ontbreken van de samenvatting aan het begin van de afronding hadden huisartsen uiteenlopende meningen. Enkele huisartsen gaven aan dat zij geen samenvatting geven, omdat het erbij inschiet. Zij zijn echter van mening dat dit wel nuttig zou zijn. Andere huisartsen gaven aan dat zij deze samenvatting een overbodige toevoeging vinden.

\section{Beschouwing}

Vierdejaars studenten geneeskunde observeerden tijdens hun huisartsstage consulten van huisartsen. Dit bleek een goed bruikbare en goedkope methode en het leverde, mede door de hoge respons, veel informatie op. De gebruikte methode kent echter ook beperkingen.

Ten eerste werden de antwoorden op de vraag: "Wat zijn hierover de opvattingen van de huisarts?", door de studenten genoteerd na een gesprek met de huisarts en kunnen we niet met zekerheid zeggen dat de mening van de huisarts juist is weergegeven. Ten tweede heeft de onderzoeksopzet tot gevolg dat elementen die wél in de praktijkconsulten voorkomen, maar niet in het onderwijsconsult, geen plaats hebben op het scoreformulier en dus niet gescoord kunnen worden. Opvallende verschillen konden studenten wel bij de open vragen kwijt, maar dit onderzoek is niet geschikt om uitspraken te doen over wat huisartsen meer doen dan wat studenten leren in het onderwijs. Ten derde kunnen ook de geobserveerde huisartsen onze resultaten vertekenen. Hoewel het een grote groep is, vormen zij geen aselecte steekproef uit de huisartsenpopulatie. Zij hebben zichzelf aangemeld als stagebegeleider en hebben blijkbaar affiniteit met onderwijs en opleiding. Bovendien is een groep van 68 huisartsen tweemaal achtereen door twee verschil- 
lende studenten geobserveerd. In beide gevallen heeft dit een onbekend effect op de resultaten.

Ten slotte zijn de resultaten van dit onderzoek niet direct generaliseerbaar naar de onderwijsprogramma's van andere faculteiten. Bij het nalopen van het onderwijsmateriaal van andere faculteiten (in 1998) bleek echter wel dat bijna alle materiaal direct of indirect op het consultmodel van Schouten gebaseerd was.

\section{Consequenties voor het onderwijs}

Twee verschillen tussen het onderwijsconsult en praktijkconsulten moeten ons inziens leiden tot aanpassing van het Groningse vaardigheidsonderwijs. Ten eerste gebeurt het in de praktijk geregeld dat de gepresenteerde klacht aanleiding geeft tot het direct doen van lichamelijk onderzoek. In het onderwijs worden op dit moment alleen consulten geoefend met klachten die zich goed lenen voor een uitgebreide anamnese, gevolgd door lichamelijk onderzoek. Het zou goed zijn om in het vaardigheidsonderwijs ook klachten op te nemen waarbij het logisch is om eerder in het consult lichamelijk onderzoek te doen. Studenten leren dan om de structuur los te laten op momenten dat dat toepasselijk of zelfs nodig is. Ten tweede zou in het onderwijs aandacht besteed moeten worden aan het voeren van vervolgconsulten. Het lijkt erop dat de structuur van het onderwijsconsult meer past bij een eerste consult dan bij een vervolgconsult. Een onderzoeksresultaat dat daarbij past, is de waarneming dat in vervolgconsulten een aantal consultonderdelen significant minder vaak aan bod komt dan in eerste consulten. Hier zit natuurlijk een zekere logica in: deze onderdelen van het consult zijn waarschijnlijk in eerdere consulten al aan bod gekomen en dus reeds bekend bij arts en patiënt. In ons onderzoek betrof $29 \%$ van de geobserveerde consulten een vervolgconsult. Bij een systematische registratie van consulten van huisartsen blijkt dit percentage 25 te zijn. ${ }^{9}$ Uit registratie van het Academisch Ziekenhuis Groningen blijkt zelfs dat $75 \%$ van de polikliniekbezoeken een vervolgconsult betreft. ${ }^{10}$ Overige verschillen hoeven ons inziens niet of in mindere mate te leiden tot veranderingen in het onderwijs. Ten eerste lijkt het ontbreken van de samenvatting in praktijkconsulten geen reden om haar ook uit het onderwijsconsult te verwijderen. Zeker bij wat complexere problemen lijkt het zinvol (voor patiënt en huisarts) om, voorafgaand aan de bespreking van de beleidsopties, de hulpvraag en diagnostische bevindingen nog eens te recapituleren. Ten tweede is het duidelijk dat praktijkconsulten minder gestructureerd verlopen dan onderwijsconsulten. Toch lijkt het belangrijk om desgewenst over een eenduidige structuur te kunnen beschikken. De huisartsen geven aan dat structuur voor hen een hulpmiddel is waar zij op terugvallen als zij er bij complexe problemen 'even niet uitkomen'. Dit fenomeen wordt ook waargenomen bij onderzoek naar redeneerprocessen van andere specialisten. ${ }^{11}$

Verder zijn er verschillen waarbij het niet noodzakelijk is om het onderwijs aan de praktijk aan te passen, omdat studenten er in de loop van de basisopleiding en vervolgopleiding vanzelf mee geconfronteerd zullen worden. Dit geldt bijvoorbeeld voor verschillen in tijdsdruk en voorkennis over patiënten. Het gesignaleerde verschil in ervaring tussen huisarts en student is een vanzelfsprekend verschil; studenten volgen juist onderwijs om kennis en ervaring op te doen. Toch valt er op dit punt tijdens de studie geneeskunde winst te boeken. Met name tijdens de co-assistentschappen zouden 
studenten meer van hun ervaringen kunnen leren. ${ }^{12-14}$ Mogelijkheden daarvoor liggen onder andere in het intensiever betrekken van studenten bij poliklinische spreekuren en het vaker observeren en systematisch nabespreken van hun consulten.

Gezien de resultaten en beperkingen van ons onderzoek lijkt het wenselijk om verder onderzoek te doen naar de praktijk van consultvoering door huisartsen. Daarbij kan bijvoorbeeld de vraag beantwoord worden wat huisartsen meer doen dan studenten in het onderwijs leren. Behalve aan verder onderzoek onder huisartsen lijkt het voor het medisch onderwijs relevant om ook onderzoek te doen naar de structuur van consulten bij andere specialismen. Studenten geneeskunde worden tenslotte opgeleid om aan elke vervolgopleiding te kunnen beginnen en van huisartsen en internisten is bijvoorbeeld bekend dat hun consulten niet op dezelfde manier verlopen. ${ }^{15}$

\section{Dankbetuiging}

Met dank aan Henk Bosveld voor de hulp bij de statistische analyses en aan Lisa Pont voor het herzien van de Engelse samenvatting.

\section{Literatuur}

1. Pols J, Aukes LC, Bootsma-de Langen et al. Medisch professionele vorming in curriculum 2000. Uitgangspunten voor het programma 1-6 [interne notitie]. Groningen: Faculteit der Medische Wetenschappen; mei 1996.

2. Schouten JAM. Anamnese en advies. Nieuwe richtlijnen voor de informatie-uitwisseling tussen arts en patiënt. 2e druk. Alphen aan den Rijn/Brussel: Samson Stafleu; 1988.

3. Byrne PS, Long BE. Doctors talking to patients. A study of the verbal behaviour of general practitioners consulting in their surgeries. London: H.M.S.O.; 1976.

4. Have $\mathrm{P}$ ten. Sequenties en formuleringen. Aspecten van de interactionele organisatie van huisartsspreekuurgesprekken. Dordrecht: Foris publications; 1987.
5. White JC, Levinson W, Roter D. "Oh, by the way ..." The closing moments of the medical visit. J Gen Intern Med 1994;9:24-8.

6. White JC, Rosson C, Christensen J, et al. Wrapping things up. A qualitative analysis of the closing moments of the medical visit. Patient Education and Counseling 1997;30:155-65.

7. Pols J, Andeweg ME, Boendermaker PM, Bosveld HEP, Terluin M. Een cohort studenten als onderzoeksassistent in de huisartsenpraktijk: betrouwbaarheid en validiteit van hun beoordelingen. Geaccepteerd voor publicatie in TMO, 2002.

8. Wester F. Strategieën voor kwalitatief onderzoek. Muiderberg: Coutinho; 1991.

9. Lamberts H. In het huis van de huisarts. Verslag van het transitieproject. Lelystad: Meditekst; 1991.

10. Kengetallen per 01-01-2000. Academisch Ziekenhuis Groningen.

11. Snoek JW. Het denken van de neuroloog [proefschrift]. Groningen: Rijksuniversiteit Groningen; 1989.

12. Metz JCM, Bulte JA, Paridon EJM van. Basisarts: bevoegd en bekwaam. Eindrapport van het Beleidsgericht Onderzoek Co-assistentschappen. Zoetermeer: Ministerie van Onderwijs en Wetenschappen; 1990.

13. Vereniging van Samenwerkende Nederlandse Universiteiten. Visitatierapport Geneeskunde en Gezondheidswetenschappen. Utrecht: VSNU; 1992.

14. VSNU-visitatiecommissie Geneeskunde en Gezondheidswetenschappen. Onderwijsvisitatie geneeskunde en gezondheidswetenschappen. Utrecht: Vereniging van Samenwerkende Nederlandse Universiteiten; 1997.

15. Gerritsma JGM, Smal JA. De werkwijze van huisarts en internist. Utrecht: Wetenschappelijke uitgeverij Bunge; 1982.

De auteurs:

M. Terluin, arts, als agnio verbonden aan het Refaja Ziekenhuis, Stadskanaal.

M.E. Andeweg, arts, als agnio verbonden aan het Refaja Ziekenhuis, Stadskanaal.

P.M. Boendermaker, huisarts, Disciplinegroep Huisartsgeneeskunde, Faculteit der Medische Wetenschappen, Rijksuniversiteit Groningen.

J. Pols, arts-onderwijskundige, Onderwijsinstituut, Afdeling Onderwijsontwikkeling en Kwaliteitszorg, Faculteit der Medische Wetenschappen, Rijksuniversiteit Groningen.

Correspondentieadres:

M. Terluin, p/a J. Pols, arts-onderwijskundige, Onderwijsinstituut, Faculteit der Medische Wetenschappen, Rijksuniversiteit Groningen, A. Deusinglaan 1, 9713 AV Groningen, tel.: 050-3637629, j.pols@med.rug.nl. 


\section{Summary}

Introduction: Medical students at the University of Groningen, the Netherlands, are taught how to structure a patient consultation. This study investigated differences between the 'educational consultation' and real consultations in general practice and attempted to explain the differences.

Method: Fourth year medical students observed consultations of general practitioners. On a form they recorded the most striking differences between the GP consultations and the educational consultation and they answered open questions about the observed differences.

Results: All items of the educational consultation were observed in practice, but not every item came up in every consultation. The consultations in general practice were less structured. Explanations were: not all items are appropriate in every consultation, doctors generally know their patients quite well, time pressure, GPs are more experienced than students, the diagnosis is often unmistakable, there may be good reason for performing the physical examination first, many consultations in practice are follow-up consultations.

Discussion: Skill training courses should focus more on follow-up consultations and include situations where immediate physical examination is required. In this way students can learn to adopt a less structured approach when appropriate. (Terluin M, Andeweg ME, Boendermaker PM, Pols J. The structure of the consultation: education versus general practice. Dutch Journal of Medical Education 2002;21(2):50-56.) 